\title{
The de winter electrocardiographic pattern
}

\begin{abstract}
Summary
We present a clinical case of a patient, without previous cardiac history, admitted to the emergency department with chest pain at low probability for coronary artery disease. The first electrocardiogram showed high-risk changes that were mistakenly interpreted as normal; serial electrocardiograms did not show dynamic changes in STsegment or in the $\mathrm{T}$ wave. The patient remained asymptomatic and with hemodynamic stability. Ultrasensitive troponin was positive, and echocardiography reported a structurally healthy heart. Finally, the patient was submitted to diagnostic coronary angiography, evidencing involvement of the proximal anterior descending artery. After reviewing again the initial electrocardiogram, it revealed a high-risk pattern (the de Winter)
\end{abstract}

Keywords: electrocardiography, acute coronary syndrome, myocardial reperfusion, chest pain
Volume II Issue 5 - 2018

\author{
Giovanny Moncayo, ' Tatiana Arroyave, ${ }^{2}$ Diego \\ Abreo $^{3}$ \\ 'Specialist in Emergency Medicine, Hospital Pablo Tobon Uribe, \\ Colombia \\ ${ }^{2}$ General physician, Hospital Pablo Tobon Uribe, Colombia \\ ${ }^{3}$ Emergency Medicine Fellow, Universidad CES, Colombia
}

Correspondence: Giovanny Moncayo, Specialist in Emergency Medicine, Hospital Pablo Tobon Uribe, Colombia, Email jmonky76@gmail.com

Received: July 26, 20I8 | Published: September 12, 2018

\section{Introduction}

Chest pain continues to be a major reason for consultation in the emergency room, with heterogeneity in the clinical presentation that ranges from cardiogenic shock or cardiorespiratory arrest to until non-cardiac benign conditions; thus, electrocardiogram (ECG) is a valuable tool for diagnosis and risk stratification. Although it is known that the management of ST-elevation myocardial infarction (STEMI) requires urgent reperfusion, there are other ECG high-risk findings that are associated with adverse outcomes or imminent acute myocardial infarction (AMI); for this reason, the performance of a prompt coronary angiography is beneficial.

\section{Clinical case}

47-year-old man, athlete, with a history of dyslipidemia in oral lipid-lowering medication and family history of AMI in first-degree relatives at age 50 . He presented to another institution for burning discomfort in thorax; ECG, in presence of chest pain, evidenced high, symmetrical $\mathrm{T}$ waves from V2 to V5 with ascending ST depression in V2 to V5, as well as ST elevation in AVR (Figure 1). The patient was referred to our service; serial ECGs were taken without pain, with absence of dynamic changes (Figure 2); ultrasensitive troponin was positive $(2592 ; 0.0-26.4)$. With the elevation of this biomarker, myocarditis was suspected; a second troponin to perform a curve was requested, along with an echocardiogram. Control biomarker at 3 hours was 7352, and the echocardiogram was reported without pathological findings. In a reanalysis, the initial ECG was interpreted as ST equivalent with the de Winter's pattern; an urgent coronary angiography was performed, finding two lesions in anterior descendent (AD) artery, $80 \%$ each. D1 with $95 \%$ injury and distal circumflex lesion of $80 \%$. The patient completed his attention in highdependency unit, revascularized with two coronary stents, and dual anti aggregation for 18 months on an outpatient basis.

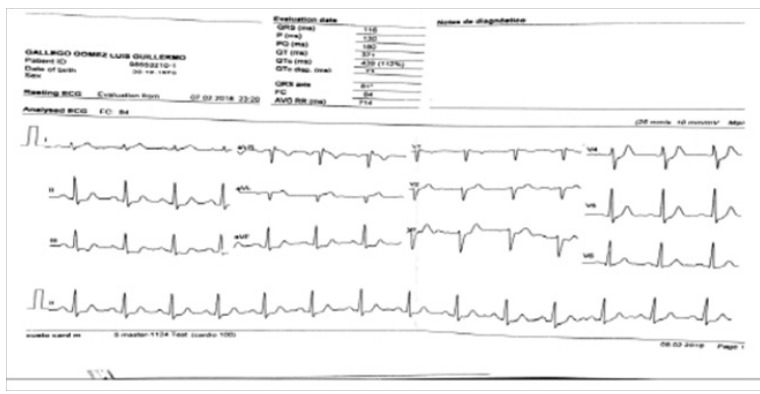

Figure I The de Winter pattern. Ascending ST-segment depression in V2 to $\mathrm{V} 5$ with high, symmetrical $\mathrm{T}$ waves in the same derivatives, associated with I $\mathrm{mm}$ ST elevation in AVR.

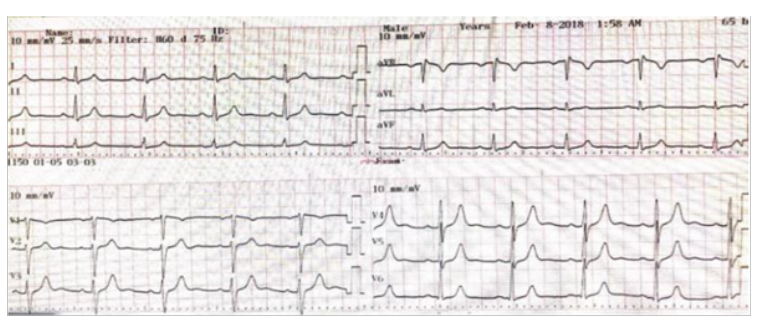

Figure 2 Electrocardiogram in patient without pain. Sinus rhythm is observed without changes in ST-segment or T wave.

\section{Discussion}

Acute coronary syndrome (ACS) is the main cause of mortality in our midst. ${ }^{1}$ Its diagnosis is based on the probability given by the clinical history, physical examination, electrocardiographic changes and biomarker. ST-segment elevation in the first ECG taken is present in one third of the patients. ${ }^{2}$ the other variations correspond to fluctuations in the T wave, ST-segment depression, branch blocks or normal ECGs. It is estimated that approximately $30 \%$ of ACS 
diagnoses are lost or delayed by a misunderstanding of high-risk patterns warranting emergency coronary angiography. ${ }^{3}$ These patterns are: posterior wall infarctions, left bundle branch block with Sgarbossa criteria, Wellens syndrome, ST-segment depression in 8 derivatives associated with ST elevation in aVR (suggesting possible trunk or three vessel disease), hyper acute $\mathrm{T}$ waves in early infarctions, and the de Winter pattern, ${ }^{4}$ being highlighted by the presentation and therapeutic implications in the patient described.

The cardiologist Robbert $\mathrm{J}$ de Winter describes as a pathognomonic sign of coronary artery diseases (CAD) a ECG pattern that corresponds to proximal occlusion of the DA artery, evidenced by STdepression from 1 to $3 \mathrm{~mm}$ in precordial derivatives V1 to V4, with high and symmetrical $\mathrm{T}$ waves in the same derivatives, associated with ST elevation in AVR; ${ }^{3}$ these changes are physiologically attributed to a variation in the Purkinje conduction fiber system that leads to a delay in intraventricular conduction; with potential wall ischemia, there is an alteration in ATP - dependent potassium channels that contributes to $\mathrm{J}$ point depression with prominent $\mathrm{T}$ waves in anterior wall. ${ }^{5}$ Other authors suggest that it is due to subendocardic ischemia that leads to a change in transmembrane action potential with progress to the subepicardium, showing a $\mathrm{J}$ point depression and slow rise in $\mathrm{T}$ wave in the ECG. ${ }^{6}$

Winter et al. in $2008^{7}$ described this electrocardiographic pattern in a series of 1532 patients; of these, $2 \%$ who underwent coronary angiography, exhibited proximal obstruction of DA; Verouden et al., ${ }^{8}$ reported the same pattern with the same percentage of the findings in the coronary angiography, and the following electrocardiographic criteria were established: ST depression greater that $1 \mathrm{~mm}$ at $\mathrm{J}$ point in precordial derivatives with continued prominent and symmetrical $\mathrm{T}$ waves, ST elevation from 0.5 to $2 \mathrm{~mm}$ in aVR, absence of another ST elevation that guides to a coronary anatomy.

It is important to recognize that there are patterns that, even without ST elevation, entail imminently to STEMI, demanding emergent intervention; similarly, subjects with the de Winter pattern tend to be men, with ages between 30 and 40 years and associated hypercholesterolemia. ${ }^{9}$ There are reports with evidence of ECG progression to anterior wall STEMI with DA occlusion. ${ }^{10}$

Whether interpreted as a high-risk pattern or a ST equivalent, it is well known that the de Winter pattern is associated with a proximal lesion of DA. Even though little is known about this pattern, these ECG changes in a patient with suspicion of ACS should lead to consideration of urgent coronary angiography and appropriate intervention.

\section{Acknowledgments}

None.

\section{Conflict of interest}

The author declare

\section{References}

1. DANE. Defunciones por grupos de edad y sexo, según departamento, municipio de residencia y grupos de causas de defunción (lista de causas agrupadas 6/67 CIE-10 de OPS).

2. Ibáñez B, James S, Agewall S, Antunes M, Bucciarelli C, Bueno H. Guía ESC 2017 sobre el tratamiento del infarto agudo de miocardio en pacientes con elevación del segmento ST. Rev Esp Cardiol. 2017;70(12):1082.e1-e61.

3. Qayyum H, Hemaya S, Squires J, et al. Recognising the de Winter ECG pattern A time critical electrocardiographic diagnosis in the Emergency Department. J Electrocardiol. 2018;51(3):392-395.

4. Lipinski M, Mattu A, Brady W. Evolving electrocardiographic indications for emergent reperfusion. Cardiol Clin. 2018;36(1):13-26.

5. de Winter RJ, Verouden NJ, Wellens HJ, et al. Interventional cardiology group of the academicmedical C. A new ECG sign of proximal LAD occlusion. N Engl J Med. 2008;359(19):2071-2073.

6. Fiol M, Bayés A, Carrillo A, et al. El "patrón de De Winter" puede evolucionar a síndrome coronario agudo con elevación del segmento ST. Rev Esp Cardiol. 2015;68(11):1039-1045

7. de Winter RJ, Verouden NJ, Wellens HJ, et al. Interventional cardiology group of the academicmedical C. A new ECG sign of proximal LAD occlusion. N Engl J Med. 2008;359(19):2071-2073.

8. Verouden NJ, Koch KT, Peters RJ, et al. Persistent precordial "hyperacute" T-waves signify proximal left anterior descending artery occlusion. Heart. 2009;95(20):1701-1706.

9. Montero J, Van-der-Kley F, Karalis I, et al. Oclusión aguda de la arteria descendente anterior proximal con patrón electrocardiográfico inusual: no todo es ascenso del ST. Cartas científicas. Rev Esp Cardiol. 2015;68(6):531-543.

10. Goebel M, Bledsoe J, Orford JL, et al. A new ST segment elevation myocardial infarction equivalent pattern? Prominent T wave and J point depression in the precordial leads associated with ST segment elevation in lead AVR. Am J Emerg Med. 2014;2(3):287:e5-8. 